
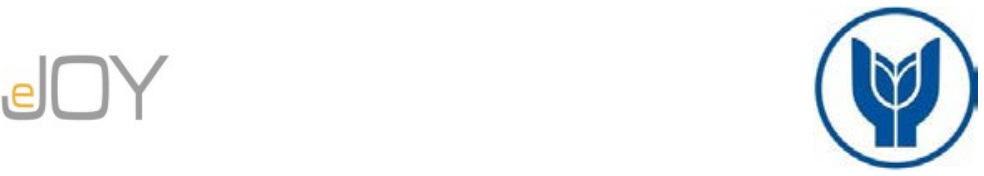

Atabek Demirhan, A., Çevik, S. / Journal of Yasar University, 2020, 15/59, 397-406

\title{
Türkiye İçin Mikro Veri Bazlı Alternatif İç ve Dış Talep Açı̆̆ı Göstergeleri
}

\section{Micro Based Alternative Output Gap Measures for Domestic and Foreign Demand}

\author{
Aslıhan ATABEK DEMIRHAN, Türkiye Cumhuriyet Merkez Bankası, Türkiye, aslihan.atabek@tcmb.gov.tr \\ Orcid No: 0000-0003-3789-4530 \\ Saygın ÇEVIK, Türkiye Cumhuriyet Merkez Bankası, Türkiye, saygin.cevik@tcmb.gov.tr \\ Orcid No: 0000-0003-1165-3085
}

\begin{abstract}
Öz: Bu çalışmada, İktisadi Yönelim Anketi firma bazlı mikro verilerini kullanılarak, Türkiye ekonomisi için oluşturduğumuz iç ve dış talep açılklarına ilişskin göstergeler sunulmaktadır. Göstergelerin oluşturulması aşamasında ilk olarak firmalar iç ve dış piyasaya yönelik üretim yapan şeklinde ayrıştırılmıştır. Daha sonra, iç ve dıș piyasa ayrımında yatırım açı̆̆ olmayıp, istihdam oranında ve satıș fiyatlarında değișiklik öngörmeyen firmalara ait kapasite kullanım oranlarının ăğrlıklı ortalaması enflasyonist baskı yaratmayan kapasite kullanım oranları olarak değerlendirmiş ve iç ve dış talep potansiyel çıktılarına alternatif göstergeler olarak tanımlanmıștır. Oluşturulan bu göstergelerin toplam kapasite kullanım oranlarından farkı ise iç ve dış talep kapasite kullanım açıkları olarak değerlendirilmiștir. Sonuçlar, iç ve dıș talep kapasite kullanım açıklarının ekonomideki iş çevrimlerini ve enflasyon baskılarını değerlendirmek için alternatif göstergeler olarak kullanılabileceğini ortaya koymaktadır.
\end{abstract}

Anahtar Sözcükler: Çıktı Açı̆̆ı, İç ve Dış Talep, Firma Bazlı Veri, Eğilim Anketi

JEL Siniflandirmasl: E31,E32, E52

\begin{abstract}
In this study, alternative gap indicators for domestic and foreign demand are introduced for the Turkish economy on the basis of firm-level tendency survey data. Firstly, firms are classified according to their production to the domestic and foreign market. Then, in the domestic and foreign markets distinction, capacity utilization rate for the firms that do not expect any price and employment changes together with no investment gap are determined as potential output proxies for the domestic and foreign demand and the difference with the actual capacity utilization rates are considered as alternative gap measures for domestic and foreign demand. Results provide supportive evidence for the adequacy of domestic and foreign demand capacity utilisation gaps as alternative indicators for assessing the overall state of the business cycle and inflation pressures.
\end{abstract}

Keywords: Output Gap, Domestic and Foreign Demand, Firm-Level Analysis, Tendency Survey

JEL Classification: E31,E32, E52

\section{Giriş}

Çıktı açı̆̆ı bir ekonomideki toplam üretim düzeyinin, potansiyel düzeyinden farkını ifade etmektedir. Çıktı açığının pozitif olduğu durumlarda, talep fazlalığı ortaya çıktığı, dolayısıyla ekonominin normal kapasitesinin üzerinde çalıştı̆̆ı ve bunun talep yönlü enflasyonist baskıya neden olabileceği düşünülmektedir. Diğer taraftan çıktı açı̆̆ının negatif olduğu durumlarda, ekonomide talebin zayıf kaldığı, dolayısıyla ortada bir arz fazlalığ 1 veya atıl kapasite oluştuğu, bunun da enflasyonda düşüşe neden olabileceği düşünülür. Talep ve arz arasındaki dengeyi ve dolayısı ile ekonomideki fiyat baskısını gösteren çıktı açı̆̆ı enflasyon hedeflemesi rejiminde merkez bankalarının yakından takip ettiği önemli bir göstergedir (Taylor, 1979 ve Fisher vd., 1996).

Çıktı açı̆̆ının iki bileşeninden, gerçekleşen üretim gözlemlenebilen bir gösterge iken, mevcut iş gücü, sermaye ve üretim teknolojisi ile enflasyon üzerinde bir baskı yaratmadan ulaşılabilecek en yüksek üretim düzeyini ifade eden potansiyel çıktı gözlemlenememektedir. Uygulamalı yazında çıktı açığı farklı istatistiksel ve ekonometrik yaklaşımlarla tahmin edilmektedir. İstatistiksel yaklaşımda, potansiyel çıktı uzun dönemli eğilim olarak tanımlanmakta ve uzun dönemli eğilimi tahmin etmeye dayalı istatistiksel filtreler kullanılmaktadır. Uygulamalarda ağırlıklı olarak Hodrick-Prescott (1997), Baxter-King (1999), Christiano-Fitzgerald (2003), Kaiser ve Maravall (2005) ve Beveridge ve Nelson (1981) çalışmalarında önerilen filtreleme yöntemleri yer almaktadır. Çıktı açığının tahminde, iktisadi teoriden bağımsız tamamen istatistiksel bir yöntem olması nedeni ile eleştirilen filtreleme yöntemlerine alternatif olarak, üretim fonksiyonuna dayalı yapısal ve yarı yapısal yöntemler ortaya konulmuştur. Blanchard ve Quah (1989) tarafından önerilen SVAR yaklaşımı ve Avrupa Birliği Ekonomik Politika Komitesi (EU Economic Policy Commitee) tarafindan tavsiye edilen, ayrıca OECD (Giorno vd., 1995), IMF (De Masi, 1997) ve CBO (Congressional Budget Office, 1995) gibi kurumlar tarafindan da kullanılan üretim

\section{Makale Geçmiși / Article History}

Başvuru Tarihi / Date of Application Kabul Tarihi / Acceptance Date

(C) 2020 Journal of Yaşar University. Published by Yaşar University. Journal of Yaşar University is an open access journal. There is no conflict of interest or ethical concern regarding this publication.

: 29 Aralık / December 2019

: 8 Mart / March 2020 
fonksiyonu yaklaşımı sıklıkla tercih edilen yöntemlerdendir. Yapısal model yaklaşımları her ne kadar iktisadi temellere dayanması nedeni ile tercih edilmiş olsa da birçok güçlü varsayım ve belirsizlik içermektedir (Slevin, 2001; De Masi, 1997; Chagny ve Döpke, 2001). Her iki yaklaşımın birbirine kıyasla avantaj ve dezavantajları mevcut olup hangisinin daha iyi sonuç verdiği konusunda kesin bir yargı oluşmuş değildir. Ancak her iki yöntemin de ortak eksikliği maruz kaldıkları revizyonlar ve son dönemlere ait tahminlerdeki yüksek oranlı belirsizliktir (Orphanides ve van Norden, 2002). Söz konusu belirsizliklere maruz kalmayan mikro bazlı kapasite kullanım oranlarına dayalı alternatif yaklaşım ise son dönemde yazında yerini almaya başlamıştır (Köberl ve Lein, 2011, Fessler vd., 2014, Crosilla vd., 2014, Şahinöz ve Atabek, 2016 ve Bezerra vd., 2016).

Türkiye için yapılan uygulamalı çalışmalar incelendiğinde, potansiyel çıktının farklı istatistiksel veya ekonomik yaklaşımlar kullanılarak tahmin edildiği görülmektedir. Özbek ve Özlale (2005) çalışmasında HP ve Kalman filtrelerini kullanarak çıktı açığı hesaplamışlardır. Saygılı ve Cihan (2008) çalışmalarında üretim fonksiyonu yaklaşımıyla çıktı açığını hesaplarken, Öğ̈̈nç ve Ece (2004), Sarıkaya vd. (2005), Kara vd. (2007) çalı̧̧alarında Türkiye için yarı yapısal bir model çerçevesinde Kalman filtresi ile çıktı açığını tahmin etmişlerdir. Öğünç ve Sarıkaya (2011) Bayesçi yöntemle, ErdoğanCoşar vd. (2013) temel bileşenler yöntemiyle çıktı açı̆̆ı tahmin etmişlerdir. Saraçoğlu vd. (2014) yapısal VAR (SVAR) modeli ve Uyarlanmış Hodrick-Prescott filtresi yöntemleriyle çıktı açığını tahmin etmişlerdir. Şahinöz ve Atabek (2016) ise kapasite kullanım açığına dayalı alternatif mikro bazlı yöntemi kullanarak çıktı açığı hesaplamalardır.

Çıktı açı̆̆ının ne ölçüde iç talep, ne ölçüde dış talep kaynaklı olduğunun anlaşılması para politikası tasarımı açısından oldukça önem arz etmektedir. Bu çalışmanın amacı, Köberl ve Lein (2011) ve Şahinöz ve Atabek (2016) çalışmalarında kullanılan yöntemin benzerini kullanarak, Türkiye ekonomisi için çıktı açığını iç ve dış talep bileşenlerine ayrıştırarak hesaplamaktır.

Çalışmanın bir sonraki bölümünde çıktı açığının iç ve dış talep bileşenlerinin hesaplanmasına ilişkin veri ve yönteme yer verilmiştir. Sonraki bölümde, hesaplanan iç ve dış talep çıktı açıklarına ilişkin betimsel analizler sunulmuştur. Son bölümde ise çalışmanın sonuçları tartışılmıştır.

\section{Veri ve Yöntem}

Kapasite kullanım oranı toplam üretim kapasitesinin ne kadarının kullanıldığını gösteren bir ölçüttür. Gerçekleşen üretim kapasitesi ile potansiyel üretim kapasitesinin oranı olarak da tanımlanabilen kapasite kullanım oranı çıktı açığına ilișkin bir gösterge olma özelliği taşımaktadır (Graff ve Sturm, 2010). İlk olarak, Köberl ve Lein (2011) firma bazlı kapasite kullanım oranlarını kullanarak çıktı açığına alternatif bir ölçüt geliştirmişlerdir. Şahinöz ve Atabek (2016) bu yöntemi kullanarak Türkiye ekonomisi için kapasite kullanımına dayalı alternatif bir çıktı açı̆̆ı göstergesi hesaplamışlardır. Kapasite kullanım açı̆̆ı diğer ölçütlere kıyasla uygulamada bazı avantajlar sunmaktadır. İlk olarak, kullanılan mevcut diğer birçok yöntemde potansiyel çıktının hesaplanmasında istatistiksel eğilimden arındırma yöntemleri kullanılmaktadır. Bu yöntemlerin başlıca sorunu son gözlemlerin sağlıklı bir şekilde tahmin edilememesidir. Ancak kapasite kullanım açığı doğrudan firma verilerinden hesaplandığından, son gözlemlerdeki belirsizlik problemini ortadan kaldırmaktadır. İkinci olarak, diğer çıktı açığı ölçütleri önemli revizyonlara maruz kalabilirken, kapasite kullanım açığında bu tür revizyonlar olmamaktadır. Son olarak, politika yapıcılar için çıktı açığının boyutunu mümkün olan en kısa zamanda belirlemek büyük önem taşımaktadır. Kapasite kullanım açığı anket verilerinden elde edildiği için, ilgili çeyreğe ait bilgilere bir ay gecikmeli olarak ulaşılabilmekte ve çıktı açığına ilişkin bilgiler oldukça güncel bir şekilde elde edilebilmektedir.

Kapasite kullanım oranlarına dayalı çıktı açığının yukarıda verilen avantajları göz önüne alınarak, bu çalışmada, Köberl ve Lein (2011) yöntemini kullanarak, Şahinöz ve Atabek (2016) çalışmasına benzer şekilde Türkiye ekonomisi için çıktı açığı hesaplanmıştır. Bu çalışmada diğerlerinden farklı olarak, mikro verinin avantajları kullanılarak çıktı açığı iç ve dış talep bileşenlerine ayrıştırarak ayrı ayrı hesaplanmıştır. Bu çalışmada hesaplanan iç ve dış talep kapasite kullanım açıkları Türkiye Cumhuriyet Merkez Bankası (TCMB) tarafından derlenen İktisadi Yönelim Anketi (IYA) verileri kullanılarak oluşturulmuştur. TCMB tarafindan 1987 yılı Aralık ayından bu yana aylık olarak uygulanmakta olan IYA, imalat sanayinde faaliyet gösteren firmaların geçmişe ilişkin değerlendirmelerini, mevcut duruma ilişkin görüşlerini ve geleceğe yönelik beklentilerini içeren bir eğilim anketidir. 2007 yılında gerek anket kapsamı gerekse içerikte bir takım değişiklikler yapılmıştır. Bu tarihten itibaren anket katılımcıların kapsamı genişletilmiş ve anket Türkiye İstatistik Kurumu'nun (TÜIKK) 2005 bazlı İmalat Sanayi Üretim Endeksi çerçevesindeki firmalara uygulanmaya başlamıştır. Ayrıca, anket aylık ve üç aylık olarak uygulanmaya başlanmış ve sorularda bir takım değişiklikler ve eklemeler yapılmıştır. Kapasite kullanım oranına ilişkin sorunun eklenmesi ile imalat sanayi kapasite kullanım oranı da 2007 yılından bu yana IYA çerçevesinde hesaplanmakta ve yayınlanmaktadır.

Çalışmanın ilk aşamasında, İYA'daki firmalar iç ve dış piyasaya üretim yapmalarına göre ayrıştırılmıştır. Firmaların ihracat oranları sektör ortanca ihracat değeri ile karşılaştııılmış ve ihracat oranı sektör ortanca değerinin üzerinde olan firmalar dış piyasaya yönelik üretim yapan diğer firmalar ise iç piyasaya yönelik üretim yapan firmalar olarak sınıflandırılmıştır. Daha sonra, iç ve dış piyasa ayrımında, yatırım ve istihdam açığı olmayıp satış fiyatlarında değişiklik öngörmeyen firmalara ait kapasite kullanım oranlarının ağırlıklı ortalamaları enflasyonist olmayan kapasite kullanım oranı 
(Non-inflationary rate of capacity utilization - NIRCU) olarak değerlendirmiş ve iç ve dış talep potansiyel çıktılarına alternatif göstergeler olarak tanımlanmıştır. Oluşturulan bu göstergelerin toplam kapasite kullanım oranlarından farkı ise iç ve dış talep kapasite kullanım açıkları olarak değerlendirilmiştir. İç ve dış piyasa ayrımında hesaplanabilen kapasite kullanım açıkları, çıktı açı̆̆ının kaynağının ayrıştırılmasında modelleme yöntemine alternatif bir yöntem olarak sunulmaktadır.

İlgili uygulamalı yazında yer alan mevcut çalışmalarda enflasyonist baskı yaratmayacak firmaların belirlenmesinde yatırım açığı olmayan ve satış fiyatında değişiklik öngörmeyen firmalar dikkate alınırken, bu çalışmada yatırım açığına ve satış fiyat değişikliği olmamasına firmanın istihdam oranında değiş̧iklik öngörmemesi, yani firmanın istihdam açığı olmaması koşulu da eklenmiştir. İşgücünün önemli bir üretim faktörü olması ve istihdam koşullarının firma üretim ve fiyatlama davranışları üzerindeki kilit rolü göz önüne alındığında, istihdam açığının tanıma eklenmesinin daha faydalı olacağı düşünülmüştür. Tanımda yapılan iyileştirmeye ek olarak, bu çalışmada kapasite kullanım açığı iç ve dış talep açıkları olmak üzere ikiye ayrılmıştır. İç ve dış piyasa koşullarının gerek talep gerekse maliyet ve arz yönlü genellikle farklılaştığı göz önüne alındığında, iç ve dış talep çıktı açıklarının mevcut durumun daha sağlıklı analiz edilmesinde önemli rol oynayabileceği vurgulanmalıdır. Ayrıca alternatif çıktı açığı olarak sunulan bu göstergelerin revizyona maruz kalmamaları, son döneme ilişkin belirsizlik içermemeleri ve iç-dış piyasa ayırımında izlenmeye olanak sağlaması bakımından mevcut diğer göstergelere kıyasla uygulamada politika yapıcılar için daha detaylı ve sağlıklı bilgi içeriğine sahip olduğu düşünülmektedir.

Enflasyonist baskı yaratmayan kapasite kullanım oranı (NIRCU) olarak tanımlanan potansiyel çıktının tahmini için bu çalışmada 2007 yılından bu yana 3892 firmaya ait 290399 gözlem kullanılmıştır. Firma bazında NIRCU'nun hesaplanmasında Tablo 1'de sunulan IYYA soruları kullanılmıştır.

Tablo 1. Analize Dahil Edilen İYA Soruları

\begin{tabular}{|l|l|}
\hline Soru & Cevap seçenekleri \\
\hline $\begin{array}{l}\text { Kapasite kullanım oranınız (Şu anda, fiziki kapasiteye göre, fiilen } \\
\text { gerçekleştirilen kapasite kullanımını yüzde olarak belirtiniz.) }\end{array}$ & $\% \ldots$ \\
\hline Gelecek üç aydaki iç piyasa satış fiyatı beklentiniz & Artacak, Aynı kalacak, Azalacak \\
\hline Gelecek üç aydaki istihdam beklentiniz & Artacak, Aynı kalacak, Azalacak \\
\hline $\begin{array}{l}\text { Geçmiş on iki aya klyasla, gelecek on iki ayda, sabit sermaye yatırım } \\
\text { harcaması beklentiniz }\end{array}$ & Artacak, Aynı kalacak, Azalacak \\
\hline
\end{tabular}

Kaynak: TCMB.

Geçmiş on iki aya kıyasla, gelecek on iki ayda, sabit sermaye yatırım harcaması beklentisine ilişkin IYA sorusu, sermaye stoğunda ayarlama yapması gerektiği için yüksek (düşük) kapasitede çalışan firmaların belirlenmesine olanak sağlamaktadır. Sabit sermaye yatıım harcaması beklentisini artacak (azalacak) olarak ifade eden firmalar pozitif (negatif) yatırım açı̆̆ı olan firmalar şeklinde değerlendirilmektedir. Dolayısıyla, yatırım açığı firmalar üzerindeki yatırım baskısını ölçmektedir.

Çıktı açığı tanımına uyumlu olacak şekilde, satış fiyatında ve istihdamında değişim öngörmeyen ve yatırım açı̆̆ olmayan firmalara ait kapasite kullanım oranının enflasyonist baskı yaratmayacağı varsayılmış ve firma bazında NIRCU, bu şartları sağlayan firmaların belirlenmesi ile oluşturulmuştur.

“i” firması için " $\mathrm{t}$ ” çeyreğindeki NIRCU aşağıdaki gibi tanımlamıştır:

$$
N I R C U_{i, t}=\left(C U_{i, t} \mid E_{t}\left(P_{i, t+1}\right)=0, E_{t}\left(U_{i, t+1}\right)=0, \text { Yatırım Açı̆̆ } l_{t}=0\right)^{1}
$$

Enflasyonist baskı yaratmayacak kapasite koşullarını sağlayan firmalara ait kapasite kullanım oranları aşağıda verilen iki aşamalı ağırlıklandırma yöntemi ile toplulaştırılmış ve imalat sanayinde iç ve dış piyasaya üretim yapan firmalar ayrımında enflasyonist baskı yaratmayacak kapasite kullanım oranları hesaplanmıştır.

$$
N I R C U_{t}=\sum_{j=1}^{24} s_{j} \sum_{i} w_{i j t} * N I R C U_{i j t}
$$

Burada $w_{i j t}$, i firmasının t zamanındaki $\mathrm{j}$ sektörü içindeki üretim değerine göre ağırlığını, $s_{j}$ ise NACE Rev 2 sınıflandırmasında $j$ sektörünün ağırlığını ifade etmektedir. Buna göre, NIRCU koşullarını sağlayan her firma üretim değerine göre ve faaliyet gösterdiği sektörün ağırlığına göre iki aşamalı ağırlıklandırılmıştır. Hesaplanan NIRCU potansiyel

\footnotetext{
${ }^{1}$ Köberl ve Lein (2011) çalışmasında, NIRCU tanımında hem cari dönem satış fiyatı değerlendirmesi hem de gelecek döneme ait satış fiyatı beklentilerine yer vermiştir. Ancak, IYA'da mevcut satış fiyatı değerlendirmesine ilişkin soru bulunmadığından, bizim tanımımızda sadece gelecek döneme ait satış fiyatı beklentisi yer almaktadir.
} 
kapasite kullanım oranı için bir gösterge olarak kullanılmakta ve gerçekleşen kapasite kullanım oranı ile farkı, alternatif çıktı açı̆̆ı olarak önerilmektedir. Buna göre,

$$
C U_{-} G A P_{t}^{i}=C U_{t}^{i}-N I R C U_{t}^{i}(3)
$$

Denklemde $C U \_G A P$ çıktı açığını, $C U$ toplam kapasite kullanım oranını, NIRCU enflasyonist baskı yaratmayacak kapasite koşullarını sağlayan firmalara ait kapasite kullanım oranını göstermektedir. Çıktı açı̆̆ı toplam, iç ve dış talep olmak üzere üç farklı piyasa için hesaplamıştır ( $i=$ toplam, iç piyasa ve dış piyasa).

İç ve dış talep ayrımında çıktı açıklarının hesaplanabilmesi için öncellikle, IYYA'ya katılan firmaları iç ve dış piyasaya yönelik üretim yapanlar şeklinde ayrıştırmamız gerekmektedir. Bu amaçla, firmaların ilgili yılda yurtdışı satışlarının toplam satışlar içerisindeki payı şeklinde tanımlanan ihracat oranları, ilgili sektördeki ortanca ihracat oranı ile karşılaştırılarak ortancanın üstünde ihracat oranı olan firmalar dış piyasaya yönelik üretim yapan, geri kalan firmalar ise iç piyasaya yönelik üretim yapan olarak sınıflandırılmıştır ${ }^{2}$. Bu çerçevede, 2007 yılından bu yana İYA'da yer alan firmaların ortalama yüzde 57'si iç piyasaya üretim yapan, yüzde 43'ü ise dış piyasaya üretim yapan olarak sınıflandırılmıştır. İç ve dış piyasaya üretim yapan firmalar için toplu NIRCU hesaplamasında yukarıda yer alan (2) numaralı denklem kullanılmış, firma ve sektör ağırlıkları ise her iki piyasa için ayrı ayrı hesaplanmıştır. NIRCU daha önce de belirtildiği üzere potansiyel kapasite kullanım oranı için bir gösterge olarak değerlendirilirken, kapasite kullanım açıkları (3) numaralı denklem kullanılarak hesaplanmaktadır.

\section{3. İç ve Dış Talep Ayrımında Kapasite Kullanım Açıkları}

Grafik 1'de enflasyonist baskı yaratmayacak kapasite koşullarını sağlayan firmalara ve diğer firmalara ait kapasite kullanım oranları, Grafik 2'de ise küresel krizin en belirgin şekilde hissedildiği 2008 yılı üçüncü çeyreğine göre her iki gruba ait kapasite kullanım oranlarının değişimini gösteren kapasite kullanım oranı endeksleri verilmiştir. İhracatın durağan seyrettiği 2010-2016 döneminde enflasyonist baskı yaratmayan firmalara ait kapasite kullanım oranının diğer firmalara ait kapasite kullanım oranının altında kaldığ yoğunlaştığı ve enflasyonist baskı yaratmayan firmalara ait kapasite kullanım oranının belirgin şekilde artış eğilimine girdiği görülmektedir (Grafik 1).

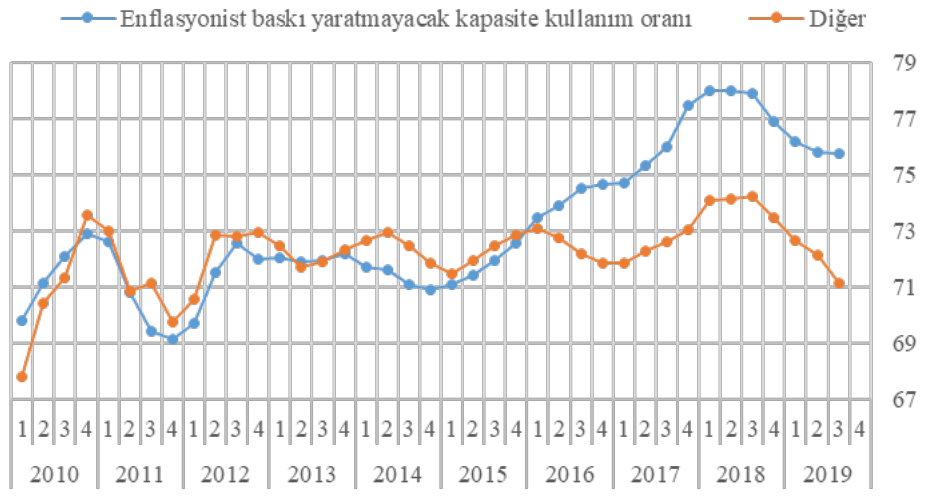

Grafik 1. Kapasite Kullanım Oranları (\%, Üç aylık)

Kaynak: TCMB, Yazarların hesaplamalarl.

\footnotetext{
${ }^{2}$ Dış piyasaya yönelik üretim yapan firmaların belirlenmesinde sektör ortanca değerinin eşik değeri olarak kullanılmasının temel sebebi yanlılı̆̆ı en aza indirgemektir. Sektöre bağlı olarak ihracat oranları farklılık gösterebilmektedir. Bu nedenle, ağırlıklı olarak dış piyasaya yönelik üretim yapan firmaların belirlenmesinde yüzde 5, yüzde 10 vb. gibi sübjektif ve tartışmaya yol açabilecek eşik değerleri kullanmak yerine sektör ortanca değerlerinin kullanılması tercih edilmiştir.
} 
Atabek Demirhan, A., Çevik, S. / Journal of Yasar University, 2020, 15/59, 397-406

$\longrightarrow$ Enflasyonist bask1 yaratmayacak kapasite kullanım oranı $\longrightarrow$ Diğer

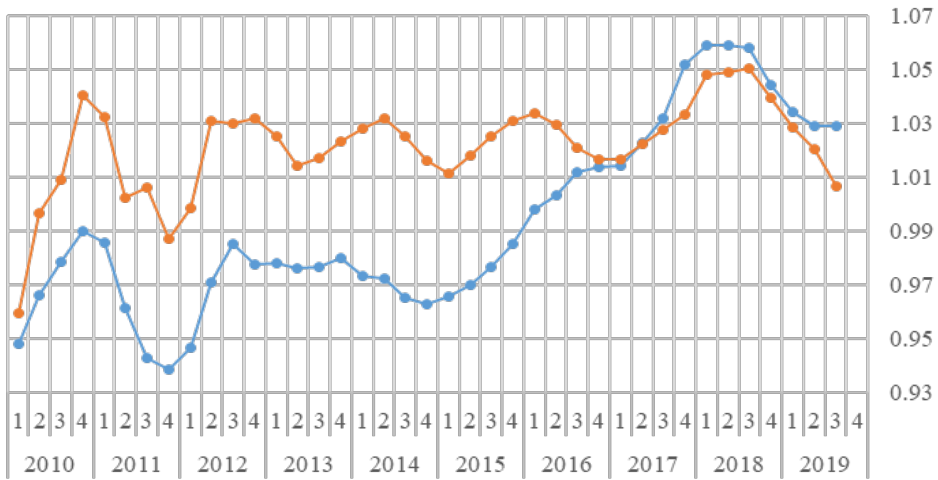

Grafik 2: Kapasite Kullanım Oranları (\%, Üç aylık, 2008:Ç3=1)

Kaynak: TCMB, Yazarlarin hesaplamalarl.

Grafik 3, enflasyonist baskı yaratmayacak özellikleri taşıyan firma sayısının toplam firma sayısına oranı ile kurun uzun dönemli ortalamadan sapması arasındaki ilişkiyi göstermektedir. Grafikten, enflasyonist baskı yaratmayan firma oranı ile kur sapması arasında negatif bir ilişki olduğu görülmektedir. Kurun uzun dönemli ortalamanın üzerinde olduğu dönemlerde firmalar üzerinde oluşan maliyetler enflasyonist baskı yaratmayacak firma oranının düşmesine neden olurken, aksi durumlarda enflasyonist baskı yaratmayacak firma oranı artış göstermektedir.

Sektörel olarak enflasyonist baskı yaratmayan firma oranı ile enflasyon ilişkisini sunan Grafik 4'ten de görüleceği üzere, her iki seri arasında negatif bir ilişki bulunmaktadır. Enflasyonist baskının yüksek (düşük) olduğu (enflasyonist baskı yaratmayan firma oranı düşük (yüksek) olan) sektörlerde ortalama yıllık enflasyonun düşük (yüksek) olduğu gözlenmektedir.

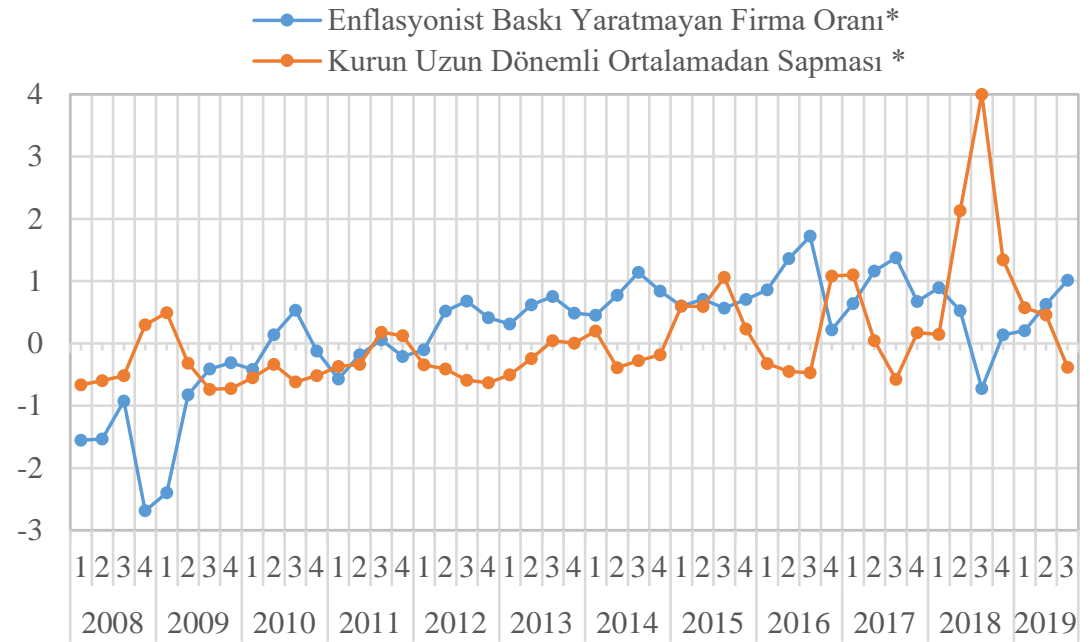

*Seriler arası karşılaştırmayı kolaylaştırmak amacıyla her iki seri ortalamalarından çıkartılıp, standart sapmalarına bölünmek suretiyle standartlaştırılmıştır. Kurun uzun dönemli ortalaması 12 aylık haraketli ortalamayı ifade etmektedir.

Grafik 3: Enflasyonist Baskı Yaratmayacak Firma Oranı ve Kur İlişkisi

Kaynak: TCMB, Yazarlarin hesaplamalart. 
Atabek Demirhan, A., Çevik, S. / Journal of Yasar University, 2020, 15/59, 397-406

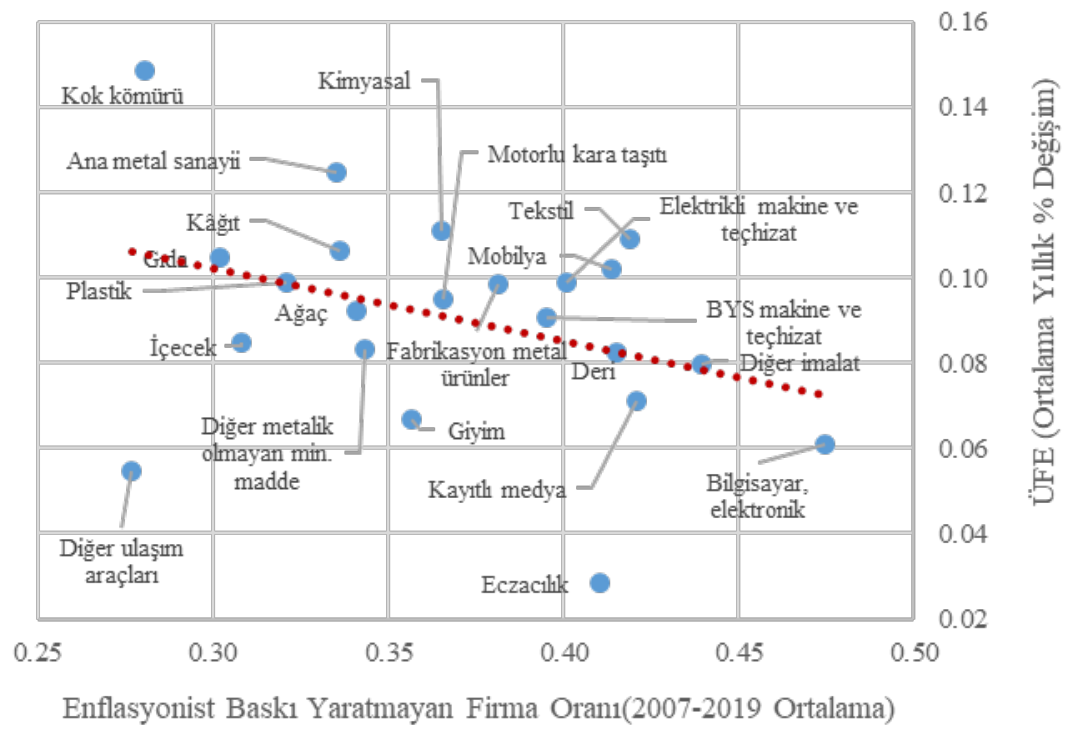

Grafik 4: Enflasyonist Baskı Yaratmayacak Firma Oranı ve Yurt İçi Üretici Enflasyonu İlişkisi** Kaynak: TCMB, Yazarların hesaplamalart.

** Grafikte tütün sektörü gösterilmemiştir.

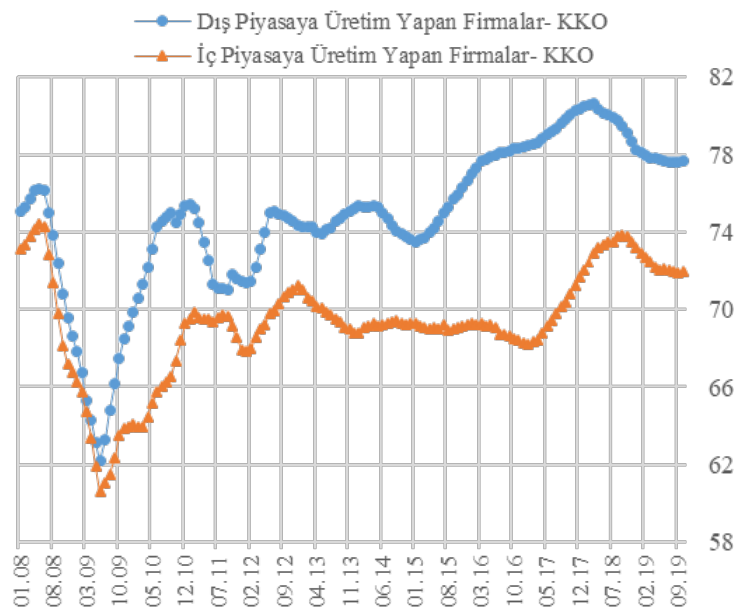

Grafik 5: Kapasite Kullanım Oranları (\%)

Kaynak: TCMB, Yazarların hesaplamalarl. 
Atabek Demirhan, A., Çevik, S. / Journal of Yasar University, 2020, 15/59, 397-406

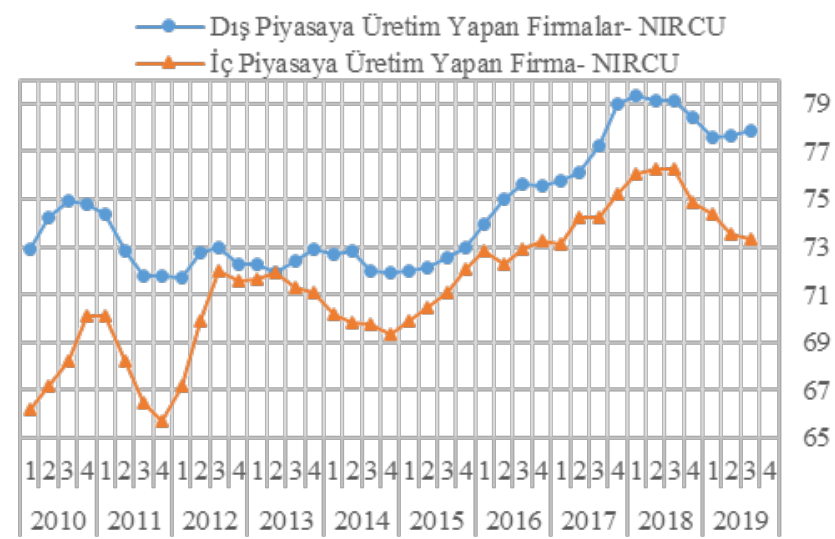

Grafik 6: Enflasyonist Baskı Yaratmayan Kapasite Kullanım Oranları (\%)

Kaynak: TCMB, Yazarlarin hesaplamalart.

İç ve dış piyasa ayrımında enflasyonist baskı yaratmayan kapasite kullanım oranları dış piyasaya yönelik üretim yapanlara ait NIRCU’nun daha yüksek seyrettiğini göstermektedir (Grafik 6). 2011-2012 yılında iç piyasaya yönelik üretim yapan firmaların NIRCU'sundaki belirgin düşüşe rağmen dış piyasaya yönelik üretim yapan firmalara ait NIRCU daha durağan bir seyir izlemiştir. 2016 yılı sonrası ise her iki piyasaya yönelik üretim yapan firmaların NIRCU'ları artış eğilimi gösterirken, 2018 yılı son çeyreğinde iç ve dış piyasalara yönelik üretim yapan firma dinamiklerinde farklılaşma dikkat çekmektedir. Grafik 7’de iç ve dış talep ayrımında hesaplanan çıktı açıkları sunulmuştur.

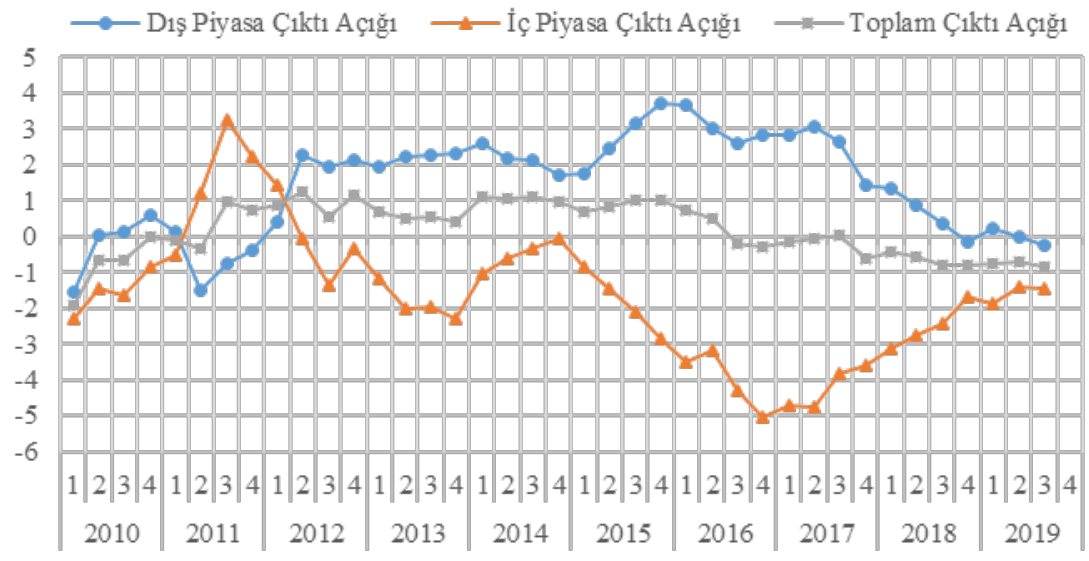

Grafik 7: İç ve Dış Talep Ayrımında Çıktı Açıkları

Kaynak: TCMB, Yazarlarin hesaplamalart.

2009 küresel finansal krizi sonrası özellikle Euro bölgesinde yaşanan durgunluk nedeniyle 2011 yılı ilk çeyreğine kadar negatif olan dış talep açığının, yeni pazarların ortaya çıkmasıyla birlikte 2011 yılı ikinci çeyreğinden 2018 yılı son çeyreğine kadar toplam çıktı açı̆̆ı üzerinde yukarı yönlü baskı yarattığı görülmektedir. 2018 yılı son çeyreğinde, Türk lirasının değer kaybetmesi sonrasında, dış talebin toplam çıktı açığını sınırlı da olsa aşağı çektiği gözlenmiştir. Diğer taraftan, iç talep açığının 2012 yılı ikinci çeyreğinden günümüze kadar negatif alan etrafında seyrettiği görülmektedir. Toplam çıktı açığ üzerinde iç talep açığının aşağı yönlü yarattığı baskı 2015 yılından 2016 yılı sonuna kadar giderek artmış, 2017 yılı başından itibaren ise iç talebi destekleyen politikalar nedeniyle azalış eğilimine girmiştir.

\section{Sonuç}

Bu çalışmada firma bazında mikro veriler kullanılarak oluşturulan ve iç ve dış piyasa ayrımında hesaplanan kapasite kullanım açıları sunulmuştur. Şahinöz ve Atabek (2016) kapasite kullanım açığının ekonomideki iş çevrimlerinin ve enflasyon baskılarının değerlendirilmesinde kullanılabilecek başarılı bir çıktı açığı göstergesi olduğunu ortaya koymuşlardır. Bu çalışmadaki sonuçlar, kapasite kullanım açığının iç ve dış piyasa ayrımında hesaplanmasının ekonomideki 
iş çevrimlerinin ve enflasyon baskılarının iç ve dış talep çerçevesinde değerlendirilmesine olanak sağladığını göstermektedir. Kapasite kullanım açığı diğer ölçütlere kıyasla uygulamada bazı avantajlar sunmaktadır. İlk olarak, kullanılan mevcut diğer birçok yöntemde potansiyel çıktının hesaplanmasında istatistiksel eğilimden arındırma yöntemleri kullanılmaktadır. Bu yöntemlerin başlıca sorunu son gözlemlerin sağlıklı bir şekilde tahmin edilememesidir. Ancak kapasite kullanım açığının doğrudan firma verilerine dayalı olması son gözlemlerdeki belirsizlik problemini ortadan kaldırmaktadır. İkinci olarak, diğer çıktı açığı ölçütleri önemli revizyonlara maruz kalabilirken, kapasite kullanım açığında bu tür revizyonlar olmamaktadır. Son olarak, politika yapıcılar için çıktı açığının boyutunu mümkün olan en kısa zamanda belirlemek büyük önem taşımaktadır. Kapasite kullanım açığı anket verilerinden elde edildiği için, ilgili çeyreğe ait bilgilere bir ay gecikmeli olarak ulaşılabilmekte ve çıktı açığına ilişkin bilgiler oldukça güncel bir şekilde elde edilebilmektedir. Diğer taraftan, kapasite kullanım oranı İYA'da 2007 yılından bu yana yer aldığından, kapasite kullanım açığının kısıtlı bir zaman dilimi için oluşturulması bu çalışmanın bir eksikliği olarak görülebilir. Bu çerçevede, çalışmanın bir sonraki aşamasında, 2007 yılından önce TÜIKK tarafından derlenen mikro bazda kapasite kullanım oranı verilerine erişim sağlanabilmesi halinde, iç ve dış piyasa ayrımında hesaplanan kapasite kullanım açığı serileri daha geriye götürülmeye çalışılacaktır. 
Atabek Demirhan, A., Çevik, S. / Journal of Yasar University, 2020, 15/59, 397-406

\section{KAYNAKÇA}

Baxter, Marianne ve Robert King. 1999. "Measuring Business Cycles: Approximate Band-Pass Filters for Economic Time Series." The Review of Economics and Statistics 81: 575-593.

Bezerra, Itaiguara ve Marco Malgarini. 2016. "A new measure of the non-inflationary rate of capacity utilisation for the Brazilian economy.” Economia Aplicada. no. 20: 441.

Beveridge, Stephen ve Charles R. Nelson. 1981. "A new approach to decomposition of economic time series into permanent and transitory components with particular attention to measurement of the "business cycle." Journal of Monetary economics. no. 7(2): 151-174.

Blanchard, Olivier Jean, ve Danny Quah. "The Dynamic Effects of Aggregate Demand and Supply Disturbances." The American Economic Review 79, no. 4 (1989): 655-73.

Congressional Budget Office. 1995. “CBO’s Method for Estimating Potential Output.” CBO Memorandum. Washington.

Döpke, Jörg ve Odile Chagny. 2001. "Measures of the Output Gap in the Euro-Zone: An Empirical Assessment of Selected Methods." Kiel Working Papers. no. 1053. Kiel Institute for the World Economy.

Christiano, Lawrence and Terry Fitzgerald. 2003. "The Band Pass Filter.” International Economic Review. 44(2): 435-465.

Crosilla, Luciana, Leproux, Solange ve Marco Malgarini. 2014. "The impact of the crisis on italian industrial capacity: an assessment based on the istat manufacturing survey," MPRA Paper. no. 67531. University Library of Munich: Germany.

De Masi, Paula R. 1997. "IMF Estimates of Potential Out-put: Theory and Practice.” Working Paper of the International Monetary Fund. no. 97/117.

Erdoğan Coşar, Evren, Kösem, Sevim ve Çağrı Sarıkaya. 2013. "Çıktı Açı̆̆ı Hesaplamalarında Filtrelere Gerçekten İhtiyacımız Var Mı?: Türkiye Örneği.” TCMB Çalışma Tebliği. no. 13/33.

Fessler, Pirmin, Rumler, Fabio ve Gerhard Schwarz. 2014. "A Micro-based Non-Inflationary Rate of Capacity Utilisation as a Measure of Inflationary Pressure- Evidence for Austria.” Empirica. 41:23-36.

Fisher, Paul G., Mahadeva, Lavan, John D. Whitley, J. D. 1996. "The Output Gap and Inflation: Experience at the Bank of England.” Paper prepared for the BIS Model Builders’ Meeting: Basle.

Giorno, C. Richardson, Richardson, P. Roseveare ve Van den Noord, P. 1995. "Potential Output, Output Gaps and Structural Budget Balances.” OECD Economic Studies. no.24: 1995/I.

Graff, Michael ve Jan-Egbert Sturm. 2010. "The information content of capacity utilization rates for output gap estimates.” CESifo Economic Studies. No. 58(1): 220-251.

Hodrick, Robert J. ve Edward Prescott. 1997. "Postwar U.S. Business Cycles: An Empirical Investigation.” Journal of Money, Credit and Banking. no. 29(1): 1-16.

Kaiser, Regina ve Agustín Maravall, A. 2005. "Combining filter design with model-based filtering (with an application to business-cycle estimation).” International Journal of Forecasting. 21(4): 691-710.

Kara, Hakan, Öğünç, Fethi, Özlale, Ümit ve Çağrı Sarıkaya. 2007. "Estimating the output gap in a changing economy." Southern Economic Journal. 74: 269-89.

Köberl, Eva Maria ve Sarah M.Lein. 2011. "The NIRCU and the Phillips curve: an approach based on micro data." Canadian Journal of Economics, Canadian Economics Association. 44(2): 673-694.

Orphanides, Athanasios ve Simon van Norden. 2002. "The Unreliability of Output Gap Estimates in Real-Time.” The Review of Economics and Statistics. 84(4): 569-583.

Ögünç, Fethi ve Çağrı Sarıkaya. 2011. “Görünmez Ama Hissedilmez Değil: Türkiye'de Çıktı Açığı.” Central Bank Review. 11(2):15-28 .

Öğünç, Fethi ve Dilara Ece. 2004. “Estimating the Output Gap for Turkey: An Unobserved Components Approach.” Applied Economics Letters. 11(3): 177-182.

Özbek, Levent ve Ümit Özlale. 2005. “Employing The Extended Kalman Filter In Measuring The Output Gap.” Journal of Economic Dynamics and Control. 29(9): 1611-1622.

Saraçoglu, Bedriye, Yigit, Özlem ve Necmettin Alpay Koçak. 2014. "Türkiye İçin Çikti Açigi Tahmininde Alternatif Yöntemler.” Business and Economics Research Journal. 5(3): 1-43.

Sarıkaya, Çağrı, Öğünç, Fethi, Ece, Dilara, Kara, Hakan ve Ümit Özlale. 2005. "Estimating Output Gap for the Turkish Economy." Central Bank of the Republic of Turkey Working Papers. no. 0503.

Saygılı, Şeref ve Cengiz Cihan. 2008. "Türkiye Ekonomisinin Büyüme Dinamikleri: 1987-2007 Döneminde Büyümenin Kaynakları, Temel Sorunlar ve Potansiyel Büyüme Oranı.” TÜSİAD Araştırma Raporları Serisi. no. T/2008-06/462.

Slevin Geraldine. 2001. "Potential output and the output gap in Ireland." Central Bank of Ireland Research Technical Papers. no. 5/RT/01.

Şahinöz, Saygın ve Aslihan Atabek. 2016. "An alternative micro-based output gap measure for Turkey: The capacity utilisation gap." Economics Letters. 143(C): 44-47. 
Atabek Demirhan, A., Çevik, S. / Journal of Yasar University, 2020, 15/59, 397-406

Taylor, John. 1979. “Estimation and Control of a Macroeconomic Model with Rational Expectations.” Econometrica. 47(5): 1267-86. 